\title{
EL HUMANISMO FILOSÓFICO EN LA REGIÓN NOA-ARGENTINA: SUS PROYECCIONES EN LA EDUCACIÓN UNIVERSITARIA
}

\author{
HUMANISMO FILOSÓFICO NA REGIÃO NOA-ARGENTINA: SUAS PROJEÇÕES NO ENSINO \\ UNIVERSITÁRIO
}

\section{PHILOSOPHICAL HUMANISM IN THE NOA-ARGENTINA REGION: ITS PROJECTIONS IN UNIVERSITY EDUCATION}

\author{
José Guzzi ${ }^{1}$ \\ Gloria Silvana Elias ${ }^{2}$ \\ Leonardo Gustavo Carabajal ${ }^{3}$
}

\begin{abstract}
Resumen: El escrito indaga sobre la presencia del movimiento humanista occidental en la formación de los intelectuales de los siglos XX y XXI en la región Norte de Argentina, a partir de analizar los humanismos que propusieron tres filósofos icónicos en su rol como docentes universitarios, a saber: Alberto Rougès, Samuel Schkolnik y Gaspar Risco Fernández. Nuestro propósito es poner en valor lo que cada uno entendió por condición humana, y cómo a partir de ello, llevaron a cabo una vida intelectual comprometida con lo que fuera una sociedad posible para nuestra región y nuestra educación.
\end{abstract}

Palabras clave: Humanismo. Educación. Rougès. Schkolnik. Risco Fernández

Resumo: $O$ artigo investiga a presença do movimento humanista ocidental na formação de intelectuais dos séculos 20 e 21 na região norte da Argentina, com base em uma análise dos humanismos propostos por três filósofos icônicos em seu papel de professores universitários, a saber: Alberto Rougès, Samuel Schkolnik e Gaspar Risco Fernández. Nosso objetivo é valorizar o que cada um entendeu como uma condição humana e, a partir daí, eles levaram uma vida intelectual comprometida com o que era uma sociedade possível para nossa região e nossa educação.

Palavras-chave: Humanismo. Educação. Rougès. Schkolnik. Risco Fernández

\footnotetext{
${ }^{1}$ Universidad Nacional de Tucuman. San Miguel de Tucumán, Tucumán, Argentina.

2 Universidad Nacional de Jujuy/Consejo Nacional de Investigaciones Científicas y Técnicas - CONICET/UNJU. San Salvador de Jujuy, Jujuy, Argentina.

${ }^{3}$ Universidad Nacional de Jujuy. San Salvador de Jujuy, Jujuy, Argentina.
} 
Abstract: The paper investigates the presence of the western humanist movement in the training of intellectuals of the 20th and 21st centuries in the Northern region of Argentina, based on an analysis of the humanisms proposed by three iconic philosophers in their role as university teachers, namely: Alberto Rougès, Samuel Schkolnik and Gaspar Risco Fernández. Our purpose is to value what each one understood as a human condition, and how, based on this, they carried out an intellectual life committed to what was a possible society for our region and our education.

Keywords: Humanism. Education. Rougès. Schkolnik. Risco Fernández

\section{INTRODUCCION}

Con el propósito de pensar en nuevos humanismos (REBOK, 1992) ${ }^{4}$ dado el periodo de excepcionalidad que atravesamos como sociedad, hemos creído propicio poder reflexionar sobre los trayectos humanistas que estuvieron presentes en la región Norte de Argentina, específicamente en la provincia de Tucumán, en lo que es la principal institución de educación universitaria de dicha región, esto es, la Universidad Nacional de Tucumán (UNT). Dicha Universidad se halla ubicada en una marginalidad geográfica, si entendemos que en la Argentina la relación centro/periferia se demarca entre la hegemonía del sector Atlántico y portuario de Buenos Aires y el resto del interior. Lo interesante es que, pese a su marginalidad, la conformación de la tradición filosófica tucumana se vio directamente influenciada por intelectuales europeos desterrados por razones ideológicas en los períodos de las grandes guerras. En efecto, en julio de 1937, huyendo de la persecución franquista, llegó a Tucumán el filósofo español Manuel García Morente, quien llevó a cabo la creación del departamento de filosofía, base de la posterior creación de la Facultad de Filosofía y Letras. En 1938 retornó a su país por motivos personales para ingresar como monje de clausura. Pese a que solo estuvo un año en Tucumán, su influencia fue central en el campo filosófico. Un año después de su partida se publicaron sus clases orales, tituladas Lecciones preliminares de filosofía, editadas por Risieri Frondizi y Eugenio Pucciarelli, quienes reemplazaron a Morente en las tareas docentes (VANELLA, 2013). Un segundo caso es el de Rodolfo Mondolfo (MONDOLFO, 1956; 1962;

\footnotetext{
${ }^{4}$ Siguiendo a Gabriela Rebok podemos señalar un humanismo histórico que se clasifica del siguiente modo: a) el humanismo romano, expresado en la figura de Cicerón promovía la humanitas, retomando la paideia griega como una alternativa a la crisis de transición entre la república y el imperio; b) la segunda etapa es el humanismo renacentista, que posee como obra fundacional de Pico della Mirándola, De dignitatis hominis, de 1486, donde se exalta la libertad humana; y c) el neohumanismo, que surge en la llustración con Rousseau, Winckelmann, Herder, Humboldt.
} 
1968; 1969) ${ }^{5}$, quien exiliado de Italia ${ }^{6}$, llegó a la Argentina en 1939, y trabajó en diferentes universidades del país. En 1948, desarrolló actividades intelectuales en la facultad de Filosofía y Letras de Tucumán. Este conjunto de intelectuales permitieron forjar lo que Francisco Romero denomina como "normalidad filosófica", y es recuperado por una filósofa tucumana que entiende ello como aquel momento histórico en que las condiciones sociológicas posibilitan la pausa teórica del pensador que se dedica a reflexionar (PIOSSEK PREBISCH, 1988, 10-11) ${ }^{7}$. Gracias a esta normalidad filosófica surgió un trabajo intelectual de traducciones, lecturas hermenéuticas de textos foráneos, etc., que permitió la posibilidad de que otros intelectuales tengan lugar.

Por ello, es que este escrito consiste en mostrar, en la vertiente del humanismo de corte europeo, las ideas rectoras que al respecto desarrollaron tres filósofos tucumanos durante los siglos XX y XXI, a saber: Alberto Rougès, Samuel Schkolnik y Gaspar Risco Fernández, con el fin de poner en estima lo que cada uno entendió por condición humana, y cómo a partir de ello, llevaron a cabo una vida intelectual comprometida con lo que fuera una sociedad posible. Sostenemos que la perspectiva valorativa de lo humano que cada uno de estos intelectuales supo elaborar en su producción intelectual, se tradujo en lo que ellos entendieron como lo posible de esperar como sociedad y como proyecto vital compartido. Tales horizontes de sentido fueron capaces de transmitirlos y ponerlos a consideración de la sociedad tucumana a partir de su producción escrita y su docencia universitaria, evidenciando, cada cual en su estilo, un profundo compromiso con la condición humana.

\section{NOCIÓN GENERAL DE HUMANISMO}

Para poder comprender cabalmente los humanismos que hallamos presentes en estos docentes filósofos, y que, a la vez, entendemos que evidencian los suelos de valores que surcan la región Norte de Argentina, nos resulta necesario poder reseñar, aunque más no sea brevemente, desde una perspectiva histórica, lo que fue el humanismo.

El humanismo clásico fue una corriente filosófica y artística con un marcado antropocentrismo, cuyo fin consistió en exaltar el valor universal de la dignidad humana. El término

\footnotetext{
${ }^{5}$ Rodolfo Mondolfo fue un filósofo italiano ampliamente reconocido. Para la comunidad hispanohablante fue muy importante la traducción de la obra de Hegel Ciencia de la lógica, ed. Hachette, 1954, así como toda su obra vinculada al pensamiento antiguo.

${ }^{6}$ Mussolini decreta una prohibición en las tareas docentes a los profesores judíos.

${ }^{7}$ En nuestro caso, esta es una pausa obligada porque en la actualidad (abril-mayo de 2020) la humanidad entera está atravesando la pandemia ocasionada por el COVID-19 y la correspondiente cuarentena.
} 
Humanismus fue usado por primera vez por Niethammer a principios del siglo XIX (FERRATER MORA, $1999)^{8}$. Sin embargo, existen antecedentes más remotos de palabras que guardan una estrecha cercanía con el concepto de dignidad humana. El término humanismo goza de una amplia gama de significaciones. Se puede hablar de un humanismo literario, filológico, naturalista, individualista, universalista, societario (BUNGE, 1996), ateo (expresado en el pensamiento de autores de la talla de Feuerbach -humanismo materialista-, Marx -humanismo antiteístico-, Nietzsche -humanismo nihilista-, y Freud -humanismo científico-), existencialista (cuyas fundamentales figuras fueron, entre otros, Kierkegaard y Sartre), y las variantes del humanismo contemporáneo: el latino, el anglosajón, el oriental, el islámico y el eslavo. Como puede apreciarse, son muchas y variopintas las perspectivas desde las que podemos abordar esta interesante temática. Ahora bien, a pesar de (y salvando) las diferencias, las distancias y los tiempos marcados, pensamos que la característica principal que puede señalarse como un punto en común entre todos y cada uno de estos tipos de humanismos es la preocupación por lo que sea el ser humano y lo que ello signifique.

Siguiendo a Eudaldo Forment Giralt (FORMENT GIRALT, 1988), puede vislumbrarse que el término "humanismo" etimológicamente proviene de "humano" y que tiene varios significados. Para este autor, en un primer sentido, "humanismo" se refiere al cultivo de la lengua y la literatura grecorromana. Ampliando el margen de significaciones, este concepto expresa cualquier movimiento cultural que tenga por finalidad estudiar la cultura clásica grecorromana en general. En un sentido aún mayor, los historiadores del siglo XIX han añadido la noción de amor a la cultura clásica y la exaltación de lo natural: "a la palabra 'humanismo' se la hacía derivar de 'humano', porque se contraponía a la interpretación cristiana y por tanto, sobrenatural, una concepción meramente natural del hombre, desligada de toda religión" (FORMENT GIRALT, 1988, 145). Un claro ejemplo de esto puede verse en la relación que guarda la educación como paideia con el significado del cosmos griego. Para Jaeger (JAEGER, 1993) el espíritu del pueblo griego se plasmaba en la paideia, como ideal de ilustración de los jóvenes con la palabra, el ritmo y la armonía buscando el equilibrio de las fuerzas formadoras del alma (JAEGER, 1993) ${ }^{9}$. Se puede hablar de un humanismo helénico lo que concentraría los valores del mundo griego, y de un humanismo semita concentrado en la idea de religión y libertad. En el mundo romano la noción de humanismo se vinculó con la

\footnotetext{
${ }^{8}$ Niethammer entendía al humanismo como el estudio de las lenguas y autores clásicos, específicamente latín y griego. ${ }^{9}$ El logos universal capaz de mentar la esencia de todas las cosas se transformaba en ideal autoconsciente de educación y, dicha autoconciencia, se plasmaba en un objetivo: esculpir el alma a partir de la imagen de un cosmos perfecto. He aquí lo más digno de aspiración: el dominio de sí como cultivo y templanza del alma. Quizás sea éste el sentido de la afirmación de Jaeger: "el pueblo griego es entre todos antropoplástico". (JAEGER, p. 11).
} 
humanitas, ésta era el modelo para alcanzar la esencia propia del hombre, razón por la cual la paideia griega era el prototipo de educación del ciudadano romano. Por otro lado, el pensamiento patrístico y medieval consideraba al homo como una criatura que gozaba de los privilegios más elevados de la creación, y su analogía fundada en la imagen y semejanza con el creador se determinaba por la razón, el libre albedrío y, en ciertos casos, por la voluntad. Tales corrientes, la griega, la romana y la cristiana, confluyeron en el Renacimiento dando un nuevo impulso al humanismo, donde la obra de Pico della Mirándola se configuró en las bases de una defensa de la dignidad humana. Es precisamente en el Renacimiento de los siglos XV y XVI donde surge propiamente la noción de humanismo y vuelve a cobrar significado en el romanticismo alemán. Aquí, el concepto de formación o de paideia reaparece en el vocablo bildung. Entendido como formación, este concepto no sólo significa el cultivo de ciertas capacidades sino que se entiende como la formación humana con una aspiración a un espíritu general. El proceso de formación contiene como modelo la tradición; según Gadamer, el concepto de bildung guarda un sentido histórico y de conservación cuyo interés es central para las ciencias del espíritu (GADAMER, 1977, 40).

Ahora bien, un emblema del humanismo contemporáneo es la tesis sartreana donde la existencia precede a la esencia en El existencialismo es un humanismo, el cual implica centrar "a todo hombre en posesión de lo que es, y asentar sobre él la responsabilidad total de su existencia" (SARTRE, 1980, 61). En Sartre resuenan los ecos de un existencialismo que propulsa el uso de la libertad aunado a la responsabilidad, no sólo como una acción individual, sino como una responsabilidad por el otro, por la humanidad toda. Finalmente, se puede pensar en una crítica al humanismo clásico como la de Lévinas en su cuestionamiento a la metafísica occidental, o bien, la deconstrucción de Derrida que retorna a los pliegues ocultos de aquello sentidos que fueron velados en el tiempo, como su crítica a la noción eurocéntrica de tolerancia.

Tal es, de un modo acotado, el concepto de humanismo: el ideal de realizar o plasmar por medio de la formación de las humanitas, lo que sea la dignidad humana. 
2. EL HUMANISMO EN EL PENSAMIENTO ARGENTINO DE LA PRIMERA PARTE DEL SIGLO PASADO: ALBERTO ROUGÈS

Alberto Rougès ${ }^{10}$ representa una figura clave del pensamiento situado en el noroeste argentino en la primera parte del siglo XX. En 1914, fue miembro fundador de la Universidad de Tucumán, conjuntamente con Juan B. Terán, Miguel Lillo, Ernesto Padilla, Juan Heller, entre otros. Su pensamiento, influido por la filosofía de Bergson, de Blondel, de Nietzsche, de Boutroux, de Poincaré, de Ortega y Gasset entre otros (GOTTHELF, 1967, 89), se encuentra configurado por la crítica de principios del siglo XX tanto al positivismo como al cientificismo mecanicista. Su obra escrita se basa en artículos y ensayos, culminando en su único libro y obra cumbre de 1943 Las jerarquías del ser y la eternidad (GOTTHELF, 1967, 96) ${ }^{11}$. Probablemente, la antigua aporía entre el ser y el devenir, subyace como problemática de su reflexión filosófica.

Es central, como llave de acceso en la comprensión del pensamiento de Rougès, aclarar su concepción sobre lo real y su postura con respecto a la división diltheana referida a las ciencias del espíritu y las ciencias de la naturaleza. En su ensayo Educación y tradición, de 1938, Rougès demuestra su desazón al comparar los diversos fenómenos culturales -positivismo y espiritualismoy las opuestas escalas de valores que estos sostenían. Positivismo versus Espiritualismo, "tener más" frente a "ser más"12. De ahí la apuesta de Rougès por los jóvenes, los que, a partir de la educación, pudieran rebelarse frente al mercantilismo tecnocrático, y por los dirigentes, a quienes responsabiliza del deber imperioso de salvar la vida espiritual. Esta división entre positivismo y

\footnotetext{
${ }^{10}$ Nació el 23 de octubre de 1880, en San Miguel de Tucumán. Su infancia transcurrió en un ambiente de campo, en Santa Rosa, al sur de Tucumán, junto a la fábrica de azúcar de sus padres. Perteneció a la Generación del Centenario. En 1914, fue miembro fundador de la Universidad de Tucumán, conjuntamente con Juan B. Terán, Miguel Lillo, Ernesto Padilla, Juan Heller, entre otros. Rougès fue un gran amigo de Ernesto Padilla y Juan B. Terán (a partir de cuya amistad se irrigaron muchas iniciativas culturales, como la creación del Instituto Miguel Lillo, el censo escolar de la Nación de 1931, el estudio de la flora argentina y de los aspectos sociales de la educación del país, etc.); de Juan Alfonso Carrizo (sabemos que de esta fértil amistad nacieron los Cancioneros Tradicionales -unos de los documentos históricos, sociales y espirituales más importantes en los últimos tiempos-, el Instituto Tradicional de la Tradición, entre otros). El 20 de abril de 1945, Rougès se hizo cargo del Rectorado de la Universidad de Tucumán, y mientras pronunciaba el discurso inicial, le sobrevino un ataque cardíaco totalmente inesperado. Falleció el 4 de mayo con los últimos fervores, las últimas alegrías y las últimas penas. Para la vida de Rougès nos basamos en el libro de PRO Diego F., Alberto Rougès. U.N.T., Biblioteca Central, 50 aniversario, Tucumán, Argentina, 1967.

${ }^{11}$ La obra de Rougès se compone por los siguientes artículos: "El filósofo", 1916; "La filosofía que se ve", 1921; "El filósofo de la contingencia" y "La ciencia que filosofa y la ciencia que no explica" de 1922. En 1925 publica "El perspectivismo de Ortega y Gasset"; en 1937 "La refutación kantiana del idealismo problemático". En 1938 publica "Totalidades sucesivas" y "El poder del espíritu". En 1939 "La vejez del espíritu" y "La vida espiritual y la vida de la filosofía" en 1941 "La duración de Bergson, el tiempo físico v el acontecer físico". En 1943 publica su único libro Las jerarquías del ser y la eternidad. (GOTTHELF, 1967, 96).

${ }^{12}$ La noción de ser más será abordada concretamente en la temática de los valores según Risco Fernández. Ver páginas siguientes.
} 
espiritualismo es lo que María Eugenia Valentié denomina dualismo en dicho autor (VALENTIÉ, 1971), que se vuelve comprensible para quien sabe que los años de formación del pensador transcurrieron bajo la hegemonía del positivismo en los centros intelectuales argentinos. Este conflicto "es el que está al origen de su dualismo: a la invasión reductora del cientificismo opone la afirmación filosófica de una realidad espiritual, totalmente distinta a la realidad física" (VALENTIÉ, 1971). Frente al mecanicismo sustancialista y al fenomenismo, Rougès postula una realidad espiritual autónoma y libre, que él denomina totalidades sucesivas. Aquí el pensador retoma la noción del tiempo de Bergson para quien existe una presencia del pasado en el presente, diferencia central entre el tiempo físico y el espiritual. Mientras el acontecer físico basado en el instante carece de temporalidad, la realidad espiritual es de carácter orgánico y totalizador, lo que implica una coexistencia de pasado, presente y futuro, como una condición para que se realice el sentido. El dinamismo de tales totalidades es la característica intrínseca que también rescata Gaspar Risco en su definición de cultura, en tanto que la realidad es histórica y, por ende, dinámica, en la que el tiempo es su esencia; por ello, no sólo el presente y el futuro son lo constitutivo, sino pasado, presente y futuro en la realidad espiritual -según Rougès-; el presente se entreteje con el pasado y el futuro.

Estas estructuras dinámicas que son las totalidades sucesivas explican el fluir libre de la vida del espíritu. Dice Valentié al respecto:

"El pensar y el obrar humano conservan alguna porción del pasado y anticipan cierto futuro para que pueda cumplirse; requieren de la mutua influencia de los distintos estadios del tiempo, de modo que no sólo el pasado condiciona al futuro, sino que este pueda modificar el presente y dar sentido al pasado" (VALENTIÉ, 1971).

Dichas totalidades sucesivas se encuentran dentro nuestro, siempre que estemos en situación o actividad creadora, tratando de hacer brotar el germen de sentido abierto tanto al pasado como al futuro (ROUGÈS, 2005).

Un hombre que carezca de pasado carece de personalidad, dirá el autor. Pues bien, lo mismo ocurre con una sociedad, un pueblo, un país; si como comunidad no recuperamos, a partir de la memoria, nuestro pasado, careceremos de identidad; si no somos capaces de recrear los valores del humanismo que guiaron nuestra historia pasada, no seremos capaces de proyectarnos, de anticiparnos en un futuro nuestro y no impuesto. Dice Lucía Piossek: "el futurismo de las generaciones anteriores al Centenario hizo desestimar en la Argentina su dimensión de pasado, de 
tradición. Por eso es que nuestro pueblo -diría Rougès- ha llegado a carecer de una personalidad verdadera, de la continuidad de un "alma nacional»" (PIOSSEK PREBISCH, 1988, 174). Ese era su anhelo, lograr que a partir de la reflexión filosófica como una actitud ${ }^{13}$, se generen valores en pos de un proyecto de identidad regional y, más ampliamente, nacional. Afirma Rougès que las sociedades que carecen de este anhelo tarde o temprano caen en el abismo, o la muerte.

En Argentina, la educación nacional en general y la de Tucumán en particular, estuvieron impregnadas de una fuerte impronta positivista que la fundamentaba, especialmente en la llamada “generación del 80". Esta generación de positivistas fue juzgada y tildada de "futurista", puesto que sus pretensiones estaban dirigidas a proyectos futuros, con la firme convicción de que debían superar al pasado. Ante esta situación, se produce la reacción antipositivista, surgida especialmente a través de la iniciativa de la "generación tucumana del Centenario" (GARCÍA DE SALTOR y SUAYTER DE IÑIGO, 1993), de la que formaban parte Rougès y Juan B. Terán, entre otros. Esta reacción puede evidenciarse en las obras de Rougès, al reivindicar la autonomía de la dimensión espiritual, al intentar recobrar la memoria, los usos y las prácticas culturales dejadas de lado, buscando la consolidación de una verdadera personalidad nacional que posea un estilo propio pero que tenga en cuenta los legados de la tradición.

Así, una de las consignas básicas planteadas por el autor para que estos cambios sean posibles fue tratar de modificar la educación positivista, "una educación poseída por el fetichismo de la cantidad" (ROUGÈS, 1937, 11), es decir, aquella educación entregada a la importancia de los recursos materiales; a la exacerbación de los valores económicos (relacionada directamente con la proliferación de la codicia); a la lucha egoísta por los bienes individuales. Nuestro filósofo tucumano atisbaba un panorama perturbador y negativo para Tucumán, que sólo podía modificarse si la educación pública propusiera el afán por un conocimiento puro, desinteresado, espiritual que sea capaz de establecer las más óptimas valoraciones culturales de la tradición. De este modo, el objetivo primordial de la educación pública debía ser formar creadores de cultura y, por supuesto, un público capaz de valorarla, estimarla y apreciarla (el público, pues, sería la otra cara de una misma moneda). Señala Rougès:

La cultura no vive en libros ni en bibliotecas, la cultura vive en los que la crean y en los públicos de éstos, es decir, en los que aprecian la creación, la juzgan, la desechan o la acogen amorosamente, la internan en la entrada de su propia alma, y, por ahí,

\footnotetext{
${ }^{13}$ La noción de actitud es desarrollada por Risco Fernández. Ver páginas siguientes.
} 
en la entraña de su pueblo, donde va a formar ese fondo emocional y valorativo que caracteriza la personalidad de éste. Los creadores de cultura y su público se implican recíprocamente, se complementan, forman un todo, una estructura, que es la cultura viviente de la sociedad (ROUGÈS, 1937, 11).

En Las jerarquías del ser y la eternidad (ROUGÈS, 1962), Rougès marca una ontología de seres distribuida en una ontología de perfecciones, cuyo hilo es la noción de tiempo. La realidad física se caracteriza por ser un presente sin temporalidad, sin historicidad. Para la interpretación substancialista, los objetos que subyacen debajo de la apariencia de los fenómenos son invariables, con lo que la realidad física resulta un ser sin acontecer. Para la concepción fenomenista, existe la sucesión de los fenómenos, los cuales no se continúan unos en los otros, sino que tiene una existencia meramente puntual. La vida biológica, los animales y las plantas ocupan otros peldaños en las jerarquías de los seres, porque acumulan el pasado en el presente. Cuanto más grande es la supervivencia del pasado en los seres, más alto es el lugar que ocupan en la jerarquía establecida; la vida humana está por encima de la realidad inerte y de la biológica, pues el presente del tiempo espiritual del hombre posee el pasado y el futuro, ya que, pasado y futuro viven y obran en el presente; el peldaño más alto lo posee Dios, realidad espiritual absoluta, que es la Eternidad, no hay allí ni pasado ni futuro, sino una presencia y un presente constantes. En este caso, el tiempo es también el eje, pero el tiempo espiritual; cuanto mayor es el horizonte de pasado y futuro de la vida, más alta es su espiritualidad y mayor su aproximación a la realidad. Al respecto, dice Valentié: "Rougès determina una escala ontológica donde la suprema realidad y el supremo valor coinciden con la suma temporalidad. La culminación de toda esta tensión dinámica es la eternidad" (VALENTIE, 1971).

\section{EL HUMANISMO ECLÉCTICO DE SAMUEL SCHKOLNIK}

Samuel Schkolnik ${ }^{14}$ ha abordado problemáticas vinculadas al sentido de la vida, la preocupación por las acciones humanas, la inextricable relación entre el cuerpo y la mente, la singularidad de la condición humana. Schkolnik ejercía la filosofía tanto mediante su producción escrita como a partir de un registro oral: en sus clases, en la mesa del café, en una conversación de

\footnotetext{
${ }^{14}$ Fue Licenciado y Doctor en Filosofía por la Universidad Nacional de Tucumán (UNT), además de escritor y ensayista. Nació en esa misma ciudad en el año 1944 hasta su fallecimiento en 2010. La prolífica obra de Schkolnik incluye la publicación de sus tesis doctoral Tiempo y sociedad, el libro de ensayos y textos literarios Parker 51, una novela filosófica cuyo protagonista fue González, su entrañable personaje ficcional, Salven nuestras almas, y otro de relatos breves, de tinte filosófico, sobre todo, titulado Algunas claves, sumado a los numerosos artículos académicos, periodísticos, culturales, fundamentalmente sus contribuciones al periódico La Gaceta de Tucumán, etc.
} 
pasillo o en las vicisitudes de un encuentro callejero. Cualquier experiencia, cualquier dato -por más nimio e insignificante que pareciese- era objeto de una minuciosa reflexión filosófica, sin dejar de ser seria y -a la vez- teñida de un fino sentido del humor, de un análisis ocurrente y original, de inferencia a partir de afirmaciones sustantivas y problemáticas, hecho que hacía posible relacionarlo con las cuestiones más profundas de la vida.

Dedicarse a la enseñanza de la filosofía no sólo es un desafío, sino que, además, cuando se desarrolla con maestría, inaugura autopistas de habilidades mentales y conexiones con la realidad en quienes tienen la dicha de compartir el espacio áulico. Esa metáfora refleja, en parte, la experiencia de haber disfrutado de las clases de Schkolnik. Su enseñanza no tuvo como piedra de toque la reproducción vacua, inerte ni mimética de los filósofos clásicos, sino el modo particular de considerar y articular sus proposiciones, dispuesto al encuentro de los hallazgos entre líneas de los textos, readecuando su contexto a la originalidad de las preguntas. Así, el objeto de las reflexiones y publicaciones de Schkolnik justifican el mote de "ecléctico" que le dimos a su humanismo; humanismo encarnado en la pasión por discutir y enseñar, sobre todo, en las escolladeras de las aulas. Pero que, además, tuvo el valor de llevar a la práctica fuera de los claustros académicos, de los que incluso llegó, en parte, a renegar. Eclecticismo que supuso un abordaje surtido de temáticas: desde la problemática ética de la justicia, al lugar de Dios y la defensa del agnosticismo; desde los diferentes usos del lenguaje a la preocupación por los fenómenos sociales; desde la reflexión sobre las posiciones políticas de izquierda y derecha, a las categorías estéticas en la literatura; del tratamiento filosófico del tiempo a la tensión humana de la razón y las pasiones; de la mirada irónica sobre el humor y la envidia, a las bondades de la mortadela. Todas preocupaciones que fueron objeto de sagaz indagación crítica, de deconstrucción honesta y de una fina originalidad en su tratamiento. Para Schkolnik, "si vale la pena dedicarse a la filosofía -y la pena no es poca, como lo sabe cualquiera que viva de enseñarla- lo vale por la posibilidad de formular seriamente ciertas preguntas" (ZAVADIVKER y ZAVADIVKER, 2012, 14).

Sin lugar a dudas, el pensamiento de Schkolnik fue, en algunos aspectos, asistemático, pero no por ello menos rico. El roce metafórico entre lo filosófico, lo literario y la rigurosidad científica constituyen las bases de un pensamiento creativo, versátil, agudo y útil para estimular la reflexión profunda. Sus cavilaciones conducían indefectiblemente a repensar y desatornillar las ideas sobre los hechos planteados. 
Ahora bien, todo humanista ha de tener un telos que mueva su pensamiento y su acción. En Schkolnik, este asunto parece acarrear cierta paradoja. Comprometido con su tiempo y los problemas de su actualidad tal y como lo atestiguan sus escritos periodísticos, su visión del mundo daba cuenta, según palabras usadas por el filósofo argentino Ricardo Maliandi, de un "ácido escepticismo ético", matizado con una fina ironía. Dicho escepticismo desconfiaba de la moralidad y negaba tanto su validez como su vigencia. Maliandi consideró que la postura ética de Schkolnik era discepolista, pues creía en la validez de los valores, pero argüía que la mayoría de la gente no cree en ella y ese hecho teñía de pesimismo su postura. Desánimo, de todos modos, compatible con el escepticismo ético de la vigencia, pero de modo restringido. De allí la aparente paradoja: ¿puede un humanista ser, al mismo tiempo, pesimista? La solución a la paradoja, se desprende de las mismas palabras del filósofo marplatense: "pero, aún en el ámbito de lo ético, su también expreso reconocimiento de la dignidad humana entraña una importante restricción de esa actitud" (ZAVADIVKER y ZAVADIVKER, 2012, 127). La dignidad, en efecto, como capacidad para responder por sí mismo de manera autónoma, es condición imprescindible que hace a la persona. Aunque, como muchas de las cualidades del ser humano, la de persona también puede perderse, pensaba el filósofo tucumano: a partir de la opresión o a partir del abandono de uno mismo. El primer modo, tiene como nudo central el hecho de que existan grandes calamidades y aberraciones en la historia, siendo, por ejemplo, la tortura o el asesinato inclemente y con alevosía, una de sus caras más terribles; el segundo, se vincula al peculiar carácter angustiante, ineludible e inevitable, de la existencia humana. Por lo tanto, ese estar en la intersección entre lo finito y lo infinito hace a una de las contradicciones de nuestra naturaleza. La humana condición de persona exige, según Schkolnik, evitar cualquier intento de perder la dignidad: a) o bien, a cambio de convertirse en una cosa que se pueda intercambiar por algo equivalente, es decir, cosificarse poniéndose precio, y así perdiendo el carácter de persona; b) o bien dejándose arrastrar por ese vacío existencial que implica olvidar las razones que pueden darle sentido a la vida.

Más allá del pesimismo y el escepticismo de las ideas schkolnianas, habría que hacer lo imposible para "no ceder al vértigo saltando al vacío, ni retroceder en busca de un inexistente lugar ajeno a su influjo, sino sostenernos más bien en la cornisa y esperar, porque allí tarde o temprano el abismo volverá a dibujar nuestro perfil" (ZAVADIVKER, 2007, 131). La dignidad, desde la óptica de Schkolnik, pareciese radicar, en suma, en esto: no dejar de responder por sí mismo, aún caminando -como cualquier otro- en los bordes de la existencia y resistiendo a la caída que supone la pérdida del sentido. No basta con ser hombre para ser digno y, ergo, persona. Para Schkolnik "el esplendor 
del mundo es posible gracias a que permanece escondido el punto ciego que constituye el foco de nuestra condición de personas" (ZAVADIVKER y ZAVADIVKER, 2012, 23).

\section{EL HUMANISMO CRISTIANO DE GASPAR RISCO COMO PROYECTO PARA EL NUEVO MILENIO}

Por su parte, Gaspar Risco ${ }^{15}$ es un humanista cristiano que ha intentado, desde una óptica tomasiana, explicar qué sea la realidad espiritual que intentan comprender las humanidades. Su tarea consiste en la experiencia directa de la comprensión y traducción de los textos latinos de Tomás de Aquino, tratando de pensar, desde el universo de sentido creacionista, la condición existencial del hombre en relación con la cultura en su región particular.

Autor de una abundante e importante producción que engloba investigaciones culturales, regionales, artísticas, se ocupó de indagar entre la cultura regional y el pensamiento medieval occidental. Algunos de sus libros más destacados son Cultura y Región; Homo Patiens: las sensibilidades y las pasiones, y Ernst Ingmar Bergman: una aproximación filosófico teológica a su mundo iconográfico. Una extensa labor cultural y filosófica hace de este intelectual una persona que dedicó su vida al estudio y a diseñar acciones que promuevan el bienestar de la sociedad en general. Su propuesta humanista se centra en buscar el camino para la trascendencia humana, pues el hombre como ser encarnado, si bien tiende al deterioro entrópico -dirá Risco-, sin embargo, en tanto espíritu, es capaz de trascendencia para sí y para los demás.

El pensamiento de Risco mantuvo una continuidad con Rougès, puesto que ambos sostuvieron que la entrada al "tercer milenio" generaba nuevas circunstancias y problemáticas, que llevaba al replanteo de los paradigmas culturales heredados:

La brillante generación tucumana del centenario no podía prever los cambios radicales que darían lugar a la inédita situación de quienes ingresamos en esta década finisecular, definitivamente de cara al tercer milenio. Si hasta aquí habíamos vivido a la sombra de las instituciones

\footnotetext{
${ }^{15}$ Nació en Tucumán, el 31 de agosto de 1933. Obtuvo su título de grado como Licenciado en Filosofía en la Universidad Pontificia de Salamanca, en 1954. Asimismo, cuatro años más tarde alcanzó la Licenciatura en Teología en la misma institución. Realizó una ardua y laboriosa tarea en cursos de grado, posgrado y en sucesivas jornadas y congresos en la Universidad Nacional de Tucumán y en diferentes universidades por las que fue convocado. Fue profesor titular en la U.N.T., y en la Universidad del Norte Santo Tomás de Aquino (UNSTA), de la que fue Decano en el período 1963-1969, y Vicedecano entre 1974-1976. Ha sido el fundador del Centro de Estudios In Veritatem, proyecto que tuvo como fin la traducción española de las Quaestiones Disputatae de Veritate. Autor de una abundante e importante producción que engloba investigaciones culturales, regionales, artísticas, se ocupó de indagar entre la cultura regional y el pensamiento medieval occidental. Algunos de sus libros más notables son Cultura y Región; Homo Patiens: las sensibilidades y las pasiones, y Ernst Ingmar Bergman: una aproximación filosófico teológica a su mundo iconográfico.
} 
culturales que aquellos nos legaron, es menester que nos aboquemos en adelante a un replanteo de los paradigmas heredados, que reformulemos de una buena vez la imagen de nuestro futuro a la luz de una nueva utopía (RISCO FERNANDEZ, 1991, 21).

La constante revalorización del hombre desde el humanismo como un fin en sí, supo dar razones más que justificadas a Risco para sostener que, ante la pregunta sobre aquello que constituye al hombre en cuanto tal, su respuesta sea que lo es la dimensión espiritual. Dirá que la misma se materializa a partir de la palabra en cultura, por lo que la palabra en la tradición cultural es capaz de remontarnos a lo más profundo del pasado. El lenguaje tiene la propiedad de describir el mundo propiamente humano.

La cultura -sostiene Gaspar Risco- consiste en todo lo que cultiva o realiza en sociedad el hombre, en las cosas y las personas, para desarrollar las aptitudes humanas más allá de su estado natural. Esta noción de cultura supone una concepción de lo real, aquella que considera que el hombre es un ser abierto a la totalidad, y esta totalidad lo mueve al hombre a ser más. El ser es la realidad que impregna todas las cosas y hasta al hombre mismo, el cual se hace consciente del ser que lo desborda y encuentra, mediante la cultura, en tanto que camino para desarrollar su condición humana. La apertura a lo trascendente genera una búsqueda hacia los valores que puedan cultivar el espíritu humano. El hombre sabe que puede "ser más" y este ser más es el peregrino camino en la búsqueda de la única realidad, verdad y bien; sólo desde estas tres últimas nociones puede encontrar dirección el destino de los hombres en la evolución de su espíritu. La cultura se encuentra en estrecha relación con la historicidad del hombre, es decir, con toda la dimensión de las acciones humanas en el transcurso del tiempo. Cualquier accionar tiene un fin dado por el sentido de los valores a los que se dirige el obrar. Ahora bien, Risco concibe "por «valores» los distintos aspectos del «ser más» que precisamente entrañan una perfección o plenitud, se nos presentan como bienes y nos atraen como fines a alcanzar y realizar" (RISCO FERNANDEZ, 1991, 66). Los valores los concibe a partir de una realidad perfecta, trascendente a la naturaleza humana. En efecto, cada grupo humano recibe y crea su cultura según sus propios ethos culturales, que "consiste en el conjunto jerárquicamente organizado de los valores y actitudes que guían todo el proceso del obrar humano" (RISCO FERNANDEZ, 1991, 66). Los diversos modos de acercarse a los valores constituyen actitudes, es decir, "inclinaciones o predisposiciones estables que hacen a un sujeto inmediatamente sensible ante un determinado valor, motivándolo en procura de su consecución" (RISCO FERNANDEZ, 1991, 
66). De este modo, de cada ethos emerge una cultura con sus rasgos propios y particulares según sus propias actitudes y valores. Esto, es la causa de la problemática que se genera en los diferentes choques culturales, asunto que hace conflictiva la búsqueda de un destino común para los grupos humanos. Uno de los caminos posibles para este problema es la posibilidad del diálogo intercultural, anticipándose así Gaspar Risco a lo que luego sería un posicionamiento contundente en las filosofías latinoamericanistas.

Ahora bien, cuando planteamos el proyecto cultural de valores nos enfrentamos con un gran problema que no podemos eludir. Nos referimos al conflicto de las diferentes intersubjetividades que constituyen, cada cual desde su propia óptica, el sentido de lo real. Debido a su diversidad múltiple que, por otra parte, es lo que manifiesta la libertad de pensamiento humano sobre el mundo entran en conflicto cuando una de ellas, por encima de las otras, intenta un dominio hegemónico sobre las demás. Esta superposición de culturas llevó a Risco a investigar una alternativa que pudiera solucionar el avasallante paso que se ha realizado sobre las microculturas existentes en nuestra región de Tucumán, "la confederación diaguita-calchaquí, el de la heroica resistencia de siglo y medio contra el invasor blanco, terminó replegándose a sus nichos ecológicos" (RISCO FERNANDEZ, 1991, 198). De allí la importancia de los estudios de Risco al centrar su atención en la búsqueda del sendero para un destino en donde sea posible el diálogo intercultural, donde se opere el encuentro de dos o más estilos de vida en la comunicación de igual a igual, de los valores y bienes (RISCO FERNANDEZ, 1991, 199). Su propuesta de una estrategia de integración reside en "articular entre sí a esos distintos ethos en una unidad mayor de convergencia mediante la práctica crítico- constructiva del diálogo intercultural" (RISCO FERNANDEZ, 1991, 199). De este modo se configurarían las bases para que cada cual pudiera mantener viva su intersubjetividad y escuchar la palabra del otro.

En suma, la propuesta de Risco desde el diálogo intercultural -pero con la consciencia de que los hombres por medio de la libertad son dueños de su destino- es que urge, en cada situación histórica, buscar nuevas respuestas. La profundidad de su pensamiento humanista está en revalorizar al hombre a partir del otro, puesto que la realidad espiritual sólo se acrecienta en esta relación. Su tarea intelectual quizás consista en seguir el sendero de uno de sus grandes maestros, dando sentido al apetito de trascendencia humano a partir de los valores: "el fin de la vida contemplativa... vale decir de la verdad increada según como le es posible al que la contempla, la 
que por cierto en esta vida se ve imperfectamente, pero en la futura se verá a la perfección" (SANTO TOMAS, 1987, 122-123).

Pues bien, hasta acá hemos querido recuperar las ideas humanistas que estuvieron alimentando la formación universitaria de intelectuales y estudiantes de la facultad de filosofía y letras de Tucumán, recuperando la figura icónica de tres de sus docentes más prominentes. Hemos podido ver cómo Risco, y Rougès años antes, tuvieron muy en claro que su propuesta cultural en el camino del "ser más" no debía ser un totalitarismo que unificara en masa a los hombres, sino un principio integrador que encarrilara en este camino a todos los ethos culturales. El principio humanista en la educación sostiene esa fuerte idea de que el ser humano tiene la capacidad de la libertad, lo que lo hace ser el responsable de la marcha del todo hacia su perfección o destrucción. En este sentido, no dejar de responder por uno mismo, a pesar del pesimismo o escepticismo, ha sido la clave humanista de Schkolnik.

\section{CONCLUSIÓN}

En suma, el desarrollo de nuestra investigación ha consistido en mostrar, en la vertiente del humanismo en occidente, las ideas rectoras que al respecto desarrollaron tres filósofos tucumanos durante el siglo XX, con el fin de poner en estima lo que cada uno entendió por condición humana, y cómo, a partir de ello, llevaron a cabo una vida intelectual comprometida con lo que fuera una sociedad posible. En este sentido, afirmamos que tales filósofos tucumanos aportaron, desde su locus, elementos diferentes a dicha corriente, iniciada en el viejo mundo. En efecto, la perspectiva valorativa de lo humano que cada uno de estos intelectuales supo elaborar en su producción intelectual, se tradujo en lo que ellos entendieron, desde sus distintas perspectivas, como posible esperar de la sociedad y como proyecto vital compartido. Tales horizontes de sentido fueron capaces de transmitirlo y ponerlos a consideración de la sociedad tucumana, a partir de su producción escrita y su docencia, evidenciando, cada cual en su estilo, un profundo compromiso con la condición humana. El vínculo y el arraigo de estos tres pensadores con la educación y con la Universidad Nacional de Tucumán no solo es innegable, sino que fueron protagonistas fundamentales del sostén de las humanidades en nuestra facultad y nuestra provincia, dándole forma a la necesaria actitud de trasladar las ideas filosóficas al campo de la cultura, la educación, la ciencia y la política. 


\section{BIBLIOGRAFÍA}

BUNGE Mario, (1996), Ética, ciencia y técnica, Bs. As. Argentina: Ed. Sudamericana.

FERRATER MORA, (1999), Diccionario de filosofía, tomo II, Barcelona, España: Ed. Ariel.

FORMENT GIRALT Eudaldo, (1988). Humanismo y Esperanza. Revista Anuario Veritas. Volumen 7, Universidad Regiomontana, México.

GADAMER Hans-Georg, (1977), Verdad y método I. Trad. Ana Agud Aparicio y Rafael de Agapito, Salamanca, España: Ed. Sígueme.

GARCÍA DE SALTOR Irene y SUAYTER DE IÑIGO Adela, (1993). Algunas propuestas en la cultura tucumana gestadas en el centenario, en Revista del Departamento de Ciencias de la Educación, Año I/II, № 4, Facultad de Filosofía y Letras, Tucumán, Argentina: UNT.

GOTTHELF René, (1967). La filosofía de Albert Rougès, en Revista Cuyo. Vol. 3 Primera época, Facultad de Filosofía y Letras. Instituto de Filosofía Argentina y americana, Mendoza, Argentina: Ed. UNCu, pp. 89-155.

JAEGER Werner, (1993), Paideia. Trad de Joaquín Xirau, y Wenceslao Roces, Bs. As., Argentina: FCE. MALIANDI Ricardo, (2012). Incredulidad y alegría. En El legado filosófico de Samuel Schkolnik, ZAVADIVKER Nicolás y ZAVADIVKER Natalia (comps.), Facultad de Filosofía y Letras, Tucumán, Argentina: Instituto de Epistemología.

MONDOLFO Rodolfo, (1956), El materialismo histórico en F. Engels y otros ensayos, Bs. As., Argentina: Ed.

MONDOLFO Rodolfo, (1962), Materialismo histórico-bolchevismo y dictadura. Bs. As., Argentina: Ed. Nuevas.

MONDOLFO Rodolfo, (1968), Bolchevismo y capitalismo de Estado. Bs. As., Argentina: Ed. Líbera. MONDOLFO Rodolfo, (1969), Marx y marxismo. Estudios histórico-críticos. DE, México: FCE.

PIOSSEK PREBISCH, Lucía, (1988), Pensamiento argentino. Creencias e ideas, Instituto de Historia y Pensamiento Argentinos. Facultad de Filosofía y Letras, Tucumán, Argentina: UNT.

PRO Diego, (1967), Alberto Rougès, Biblioteca Central, 50aniversario, Tucumán, Argentina: UNT.

RISCO FERNÁNDEZ Gaspar, (1991), Cultura y Región, Centro de Estudios Regionales, Tucumán, Argentina: Ed. Instituto Internacional Jacques Maritain.

REBOK Gabriela, (1992). La disputa del ‘Humanismo' y ‘Antihumanismo' contemporáneo, en Anales de la Academia Nacional de Ciencias de Buenos Aires. T. XXVI (2), pp. 544.558.

ROUGÈS Alberto, (1937). Educación y Tradición, Prólogo al libro de Juan Alfonso Carrizo Los cantares tradicionales de Tucumán, Tucumán, Argentina: UNT.

ROUGÈS Alberto, (2005). Ensayos (1905-1945). PERILLI DE COLOMBRES GARMENDIA Elena y ROMERO Elba Estela (comps.), Centro Cultural Alberto Rougès, Fundación Miguel Lillo, Tucumán, Argentina.

ROUGÈS Alberto, (1962), Las jerarquías del ser y la eternidad, Tucumán, Argentina: UNT. 
SANTO TOMÁS, Aquino de (1986-1987), Cuestiones Disputadas Sobre la verdad, XI: Sobre el maestro, art. $4^{\circ}$ resp., (traducción de Gaspar Risco Fernández), en Notas y Documentos N9-10, Instituto Jacques Maritain, Caracas, Venezuela: Ed. Latinoamericana.

SARTRE J. Paul, (1980), El existencialismo es un humanismo, Bs. As., Argentina: Ed. Orbis.

SCHKOLNIK Samuel, (2012). Pequeño e inmenso, En El legado filosófico de Samuel Schkolnik, ZAVADIVKER Nicolás y ZAVADIVKER Natalia (comps.), Facultad de Filosofía y Letras, Tucumán, Argentina: Instituto de Epistemología.

SCHKOLNIK Samuel, (2012). El mundo, la filosofía y las instituciones, En El legado filosófico de Samuel Schkolnik, ZAVADIVKER Nicolás y ZAVADIVKER Natalia (comps.), Facultad de Filosofía y Letras, Tucumán, Argentina: Instituto de Epistemología.

VALENTIÉ María Eugenia, (1971). El dualismo en el pensamiento de Rougès, Diario La Gaceta, Tucumán, 17 de octubre.

VANELLA Liliana María, (2013). La migración intelectual de la Universidad de Tucumán en Argentina, durante el período de entreguerras, en Revista Integración y conocimiento, Núcleo de estudios e investigación en Educación superior del Mercosur, N², Córdoba, Argentina, pp. 165-178.

\section{Sobre los autores:}

\section{José Guzzi}

Profesor en Filosofía (Facultad de Filosofía y Letras de la Universidad Nacional de Tucumán). Prof. Auxiliar Docente de la Cátedra de Estética de la Facultad de Filosofía y Letras, UNT, y Prof. Adjunto de la Cátedra de Medios de Comunicación Audiovisual de la Escuela Universitaria de Cine, Video y TV, de la UNT. Integrante del Centro Interdisciplinario de Estudios Sociales, Culturales y Filosóficos. Doctorando del Doctorado de Humanidades.

Email: joseguzzifilo@gmail.com

ORCID https://orcid.org/0000-0002-2367-4302

\section{Gloria Silvana Elías}

Posdoctora en Ciencias Sociales y Humanas (UBA- Bs. As. -Argentina)- Doctora en Filosofía (UNT- TucumánArgentina). Profesora Asociada de Historia de la Filosofía Medieval y Profesora Titular de Antropología Filosófica en la Universidad Nacional de Jujuy-Argentina. Investigadora Adjunta de CONICET (Consejo Nacional de Investigaciones Científicas y Técnicas)- Argentina. Directora del proyecto de investigación Reconocimiento y alteridad: el problema del otro en Latinoamérica por SECTER-UNJU

Email: gloriaelias@hotmail.com

ORCID https://orcid.org/0000-0002-5992-844X

\section{Leonardo Gustavo Carabajal}

Doctor en Humanidades (Área Filosofía) y Lic. y Prof. de Filosofía (Facultad de Filosofía y Letras, UNT. Tucumán- Argentina). Prof. estable del Doctorado en Ciencias Sociales de la Facultad de Humanidades y Ciencias Sociales, (UNJU-Jujuy, Argentina). Co-director del proyecto de investigación Reconocimiento y alteridad: el problema del otro en Latinoamérica por SECTER-UNJU.

Email: inurbanus@hotmail.com.ar

ORCID https://orcid.org/0000-0002-9488-1528 
Recebido em: 20/05/2020 Aprovado em: 19/06/2020 Publicado em: 25/06/2020 